\title{
Oral versus intravenous rehydration therapy in severe gastroenteritis
}

\author{
J SHARIFI, F GHAVAMI, Z NOWROUZI, B FOULADVAND, M MALEK, M REZAEIAN, \\ AND M EMAMI
}

Department of Paediatrics, Bahrami Children's Hospital, Tehran University School of Medicine and Department of Pathobiology, Tehran University School of Public Health, Iran

SUMMARY A controlled, randomised trial comparing the results of oral rehydration therapy with those of intravenous fluid treatment in $\mathbf{4 7 0}$ children with severe gastroenteritis was undertaken. The oral rehydration therapy was divided into two phases-a rehydration phase that used high sodium isotonic fluid at $40 \mathrm{ml} / \mathrm{kg}$ per hour and a maintenance phase using low sodium isotonic fluid (sodium 40, potassium 30, bicarbonate 25, chloride 45, and dextrose $130 \mathrm{mmol} / \mathrm{l}$ ). The results indicate that oral rehydration treatment, used according to this protocol, is successful in treating severe diarrhoea and dehydration, and has considerable advantages over intravenous fluid therapy in reducing complications associated with the treatment of hypernatraemia, in promoting rapid correction of hypokalaemia and acidosis, in decreasing the duration of diarrhoea, and in promoting a greater weight gain at hospital discharge.

Oral rehydration therapy has been widely used for some years in treating dehydrated patients. ${ }^{1-3} \mathrm{~A}$ study in 1980 showed that oral treatment could be used successfully in severe dehydration and shock. ${ }^{4}$ We compared the results of oral rehydration therapy, according to the protocol used in the study mentioned above, ${ }^{4}$ with intravenous fluid treatment in $\mathbf{4 7 0}$ patients suffering severe forms of diarrhoea, vomiting, and dehydration.

\section{Materials and methods}

Patients. The study population consisted of 470 children aged 1 to 18 months, admitted to this hospital between April and September 1981 for severe dehydration, diarrhoea, or vomiting, regardless of their previous treatment and state of nutrition. All were initially examined by the hospital house officers (independently of the investigators) and the decision to admit them was based on their clinical assessment that severe dehydration, watery diarrhoea (greater than $10 \mathrm{ml} / \mathrm{kg}$ per hour), and vomiting (more than six times per 24 hours) were present (in accordance with the criteria suggested by the World Health Organisation). ${ }^{3}$ If two or more signs in the 'severe dehydration' category (Table 1) were present, the patient was considered to have severe dehydration. A similar guide was used for moderate dehydration. Patients were randomised either to the oral treatment group (study group) or the intravenous treatment group, which was the contiol group. The patients' biographical data, medical history and parents' written consent were obtained for all. No patient had any medical complications other than those directly related to dehydration. Thirty six per cent of the study group and $33 \%$ of the control group were below the third centile for weight according to the standards published by the National Center for Health Statistics. ${ }^{5}$

The volume of fluid given to each patient, and the frequency of vomiting were recorded. Patients were weighed on hospital admission and at discharge. Follow up studies at home were randomly performed on 334 children between October and November 1981.

Laboratory studies. Laboratory studies performed on admission included venous blood sampling for serum concentrations of sodium, potassium, chloride, and bicarbonate, stool sampling (via rectal catheter) for parasites and bacteria ${ }^{6-8}$ Follow up laboratory studies were performed 24 hours after admission and at discharge (serum sodium, potassium, chloride, and bicarbonate). For some patients these examinations were performed more than three times.

Treatment. The oral treatment protocol consisted of 
Table 1 Clinical assessment of severity of dehydration

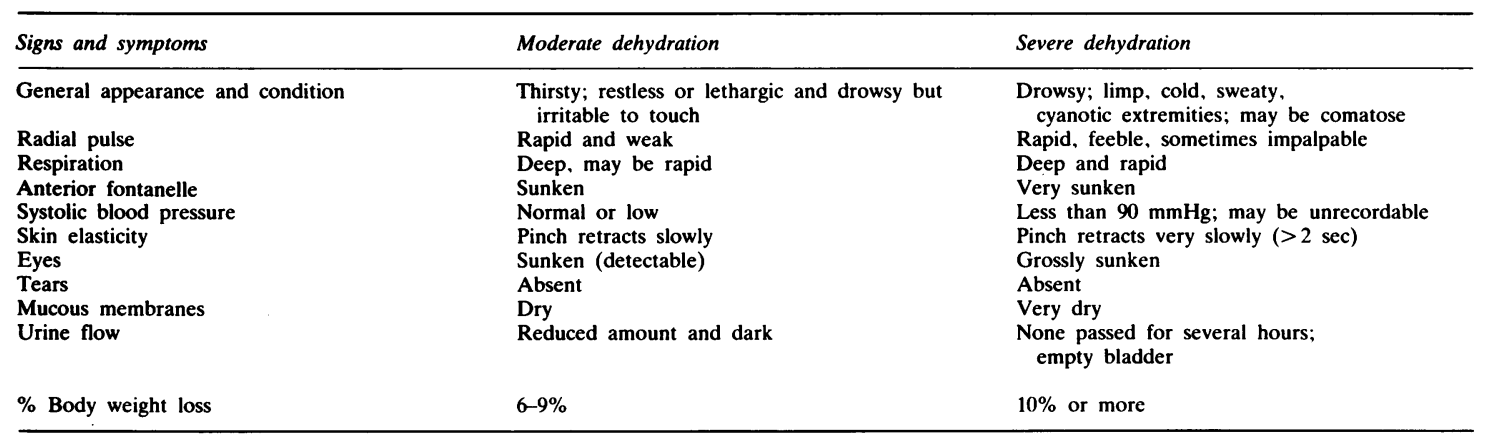

Modified from World Health Organization guide. ${ }^{3}$

two phases: (a) rehydration, and (b) maintenance treatment. ${ }^{4}$ For rehydration therapy all patients had a nasogastric tube passed and their gastric contents aspirated. Intragastric drip was started with electrolyte A solution (Table 2) at a rate of $40 \mathrm{ml} / \mathrm{kg}$ per hour (maximum $=400 \mathrm{ml} /$ hour). Administration of the electrolyte solution was continued at the same rate until all clinical signs of dehydration had resolved. This was achieved within a mean (SD) of 6 (2) hours. If within the first two hours of treatment the signs of dehydration had worsened or remained unchanged, oral therapy was stopped and intravenous treatment started. In this case, oral therapy was defined as a failure.

After complete rehydration, maintenance therapy with electrolyte B solution (Table 2) was given by bottle (but nasogastrically for those patients who could not take the solution orally) at a rate of about $250 \mathrm{ml} / \mathrm{kg}$ per 24 hours. Both solutions were made up by dissolving one prepared package in $250 \mathrm{ml}$ of tap water. In cases of severe diarrhoea, where the stool volume was more than $10 \mathrm{ml} / \mathrm{kg}$ per hour, solution A was administered instead of solution B until the volume of stool had decreased to less than $10 \mathrm{ml} / \mathrm{kg}$ per hour.

Within 24 hours the children were fed with breast or undiluted formula milk at about 10 to $20 \mathrm{kcal} / \mathrm{kg}$ per 24 hours. This amount was gradually increased to about $100 \mathrm{kcal} / \mathrm{kg}$ per 24 hours within the next few days and simultaneously the amount of solution B was decreased as needed. No intravenous solutions or other medications were used.

Patients in the control group were treated ${ }^{9}$ for shock (or to prevent its occurrence) with lactated Ringer solution: 20 to $30 \mathrm{ml} / \mathrm{kg}$ body weight was administered as rapidly as possible or within one hour in less severely ill patients. If clinical signs of shock persisted a second infusion of 20 to $30 \mathrm{ml} / \mathrm{kg}$ was given to restore circulation. Two thirds of the approximate losses of sodium and water were calculated and replaced during the first 24 hours of treatment, and the remaining one third during the second day. In addition to replacing losses, total fluid and electrolytes given during the first 24 hours and on subsequent days of treatment included replacement for both continuing normal losses and any abnormal losses from diarrhoea. In hyponatraemic dehydration, extra amounts of sodium needed to replace the additional losses were given over several days. In hypernatraemic dehydration, the amounts of normal maintenance fluid and sodium were reduced by $30 \%$ until hypernatraemia was corrected.

In general, the solutions used for this purpose contained: 25 to $60 \mathrm{mmol} / \mathrm{l}$ sodium, 15 to $35 \mathrm{mmol} / \mathrm{l}$ potassium, 0 to $35 \mathrm{mmol} / \mathrm{l}$ bicarbonate, and 20 to

Table 2 Composition of electrolyte solutions $A^{*}$ and $B \dagger(m m o l / l)$

\begin{tabular}{lllllrr}
\hline Solution & Sodium & Potassium & Bicarbonate & Chloride & Dextrose & Osmolarity (mOsm/l) \\
\hline A & 80 & 20 & 35 & 65 & 70 & 270 \\
B & 40 & 30 & 25 & 45 & 130 \\
\hline
\end{tabular}

*Made by adding the following to $250 \mathrm{ml}$ of tap water: sodium chloride, $0.6575 \mathrm{~g}$; sodium bicarbonate, $0.735 \mathrm{~g}$; potassium chloride, $0 \cdot 375 \mathrm{~g}$; and anhydrous Made by adding

+Made by adding the following to $250 \mathrm{ml}$ of tap water: sodium chloride, $0.22 \mathrm{~g}$; sodium bicarbonate, $0.525 \mathrm{~g}$; potassium chloride, $0.56 \mathrm{~g}$; and anhydrous dextrose, $5.85 \mathrm{~g}$. 
$60 \mathrm{mmol} / \mathrm{l}$ chloride in $5 \%$ dextrose in water. When the frequency and volume of stools had subsided, oral feeding of half strength milk was begun. As soon as this was tolerated without exacerbation of diarrhoea, the caloric intake (volume and strength of milk) was increased gradually until the usual dietary intake was achieved. This was accomplished within a mean (SD) time of 3 (2) days.

\section{Results}

At the time of hospital admission there were no significant differences in clinical characteristics between the study and control groups. An aetiologic agent was identified in 77 children $(33 \%)$ in the oral rehydration group and $62(26 \%)$ control patients (Table 3).

A comparison of intake, output, percentage of weight gain, and duration of diarrhoea was made for the two treatment groups (Table 4). In general, children treated with oral rehydration solution took in significantly more sodium, potassium, bicarbonate, chloride, fluid, and milk than the control children on intravenous rehydration treatment.

Table 3 Features of treatment groups on admission to hospital

\begin{tabular}{|c|c|c|}
\hline & $\begin{array}{l}\text { Study group } \\
(n=236)\end{array}$ & $\begin{array}{l}\text { Control group } \\
(n=234)\end{array}$ \\
\hline No & 236 & 234 \\
\hline Boy:girl $(\%)$ & $63: 37$ & $57: 43$ \\
\hline Body weight at discharge $(\mathrm{kg})$, mean (SD) & $6 \cdot 4(1 \cdot 7)$ & $6 \cdot 5(2)$ \\
\hline No $(\%)$ with history of vomiting & $212(90)$ & $215(92)$ \\
\hline No $(\%)$ with history of severe vomiting & $118(50)$ & $124(53)$ \\
\hline No $(\%)$ with history of severe diarrhoca & $170(72)$ & $168(72)$ \\
\hline Rectal temperature $\left({ }^{\circ} \mathrm{C}\right)$, mean $(\mathrm{SD})$ & $37 \cdot 9(0 \cdot 8)$ & $37 \cdot 8(0 \cdot 8)$ \\
\hline No $(\%)$ given antibiotics before armission & $182(77)$ & $190(81)$ \\
\hline \multicolumn{3}{|l|}{ Estimated degree of dehydration, no $(\%)$} \\
\hline Severe with signs of shock & $49(21)$ & $61(26)$ \\
\hline Moderate to severe & $151(64)$ & $152(65)$ \\
\hline Pathogens identified in stools, no $(\%)$ & $77(33)$ & $62(26)$ \\
\hline Enterotoxigenic Escherichia coli & $30(13)$ & $27(12)$ \\
\hline Salmonella & $22(9)$ & $19(8)$ \\
\hline Entamoeba histolytica & $4(2)$ & $3(1)$ \\
\hline Giardia lamblia & $8(3)$ & $5(2)$ \\
\hline
\end{tabular}

Table 4 Features of groups during treatment

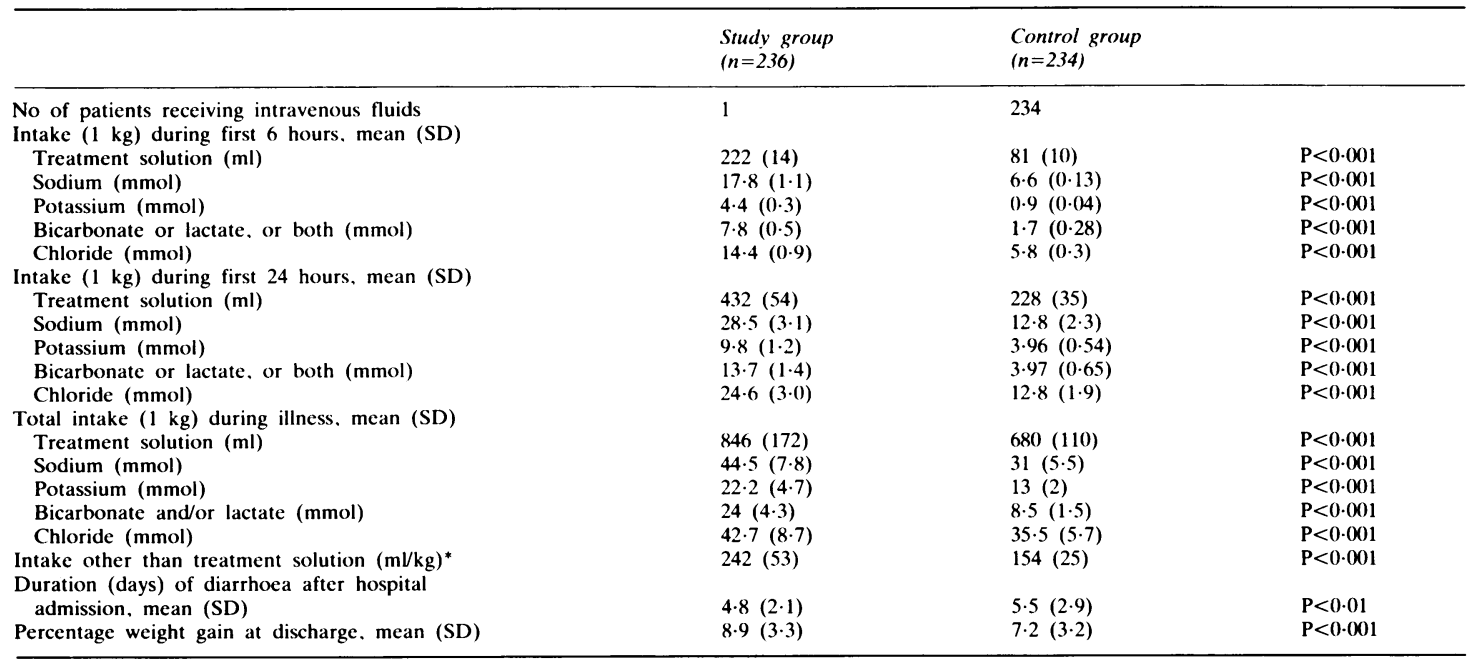

*Milk and water. 
Table 5 Concentration of serum electrolytes (mmolll) in the two treatment groups (values Mean (SD))

\begin{tabular}{|c|c|c|c|}
\hline & $\begin{array}{l}\text { Study group } \\
(n=236)\end{array}$ & $\begin{array}{l}\text { Control group } \\
(n=234)\end{array}$ & \\
\hline Sodium & $(n=178)$ & $(n=205)$ & \\
\hline On admission & $141.5(11 \cdot 7)$ & $140 \cdot 6(9 \cdot 7)$ & \\
\hline 24 hours later & $138.8(8.6)$ & $138.5(8 \cdot 7)$ & \\
\hline At discharge & $138.9(3.6)$ & $138 \cdot 7(4 \cdot 1)$ & \\
\hline Hypernatraemia $\left(\mathrm{Na}^{+}>150\right)$ & $(n=34)$ & $(n=24)$ & \\
\hline On admission & $157.5(4 \cdot 8)$ & $156(4 \cdot 6)$ & \\
\hline 24 hours later & $149(4.9)$ & $150(5 \cdot 1)$ & \\
\hline At discharge & $139(3.5)$ & $139(3.8)$ & \\
\hline Hyponatraemia $\left(\mathrm{Na}^{+}<130\right)$ & $(n=22)$ & $(n=19)$ & \\
\hline On admission & $122(4 \cdot 4)$ & $121(4 \cdot 3)$ & \\
\hline 24 hours later & $132(5 \cdot 2)$ & $129(4.9)$ & \\
\hline At discharge & $138(4 \cdot 1)$ & $138(4 \cdot 3)$ & \\
\hline Potassium & $(n=141)$ & $(n=184)$ & \\
\hline On admission & $4.2(0.9)$ & $4.0(0.9)$ & \\
\hline 24 hours later & $4.8(0.8)$ & $4.3(0.9)$ & $P<0.001$ \\
\hline At discharge & $4.6(0.4)$ & $4 \cdot 0(0 \cdot 6)$ & $P<0.001$ \\
\hline Hypokalaemia $\left(\mathrm{K}^{+}<3.5\right)$ & $(n=45)$ & $(n=52)$ & \\
\hline On admission & $2.5(0.6)$ & $2 \cdot 5(0 \cdot 6)$ & \\
\hline 24 hours later & $3.2(0.5)$ & $2.5(0.6)$ & $P<0.001$ \\
\hline At discharge & $4.4(0.4)$ & $3.4(0.5)$ & $P<0.001$ \\
\hline Hyperkalaemia $\left(\mathrm{K}^{+}>5.5\right)$ & $(n=21)$ & $(n=19)$ & \\
\hline On admission & $6 \cdot 3(0 \cdot 8)$ & $6 \cdot 3(0 \cdot 7)$ & \\
\hline 24 hours later & $6(0 \cdot 4)$ & $6(0.5)$ & \\
\hline At discharge & $5.5(0.4)$ & $5.3(0.5)$ & \\
\hline Bicarbonate & $(n=166)$ & $(n=165)$ & \\
\hline On admission & $9.9(4.8)$ & $9 \cdot 5(5 \cdot 6)$ & \\
\hline 24 hours later & $15.0(5.9)$ & $11 \cdot 7(4 \cdot 2)$ & $P<0.001$ \\
\hline At discharge & $24 \cdot 0(2 \cdot 1)$ & $20.8(3 \cdot 7)$ & $P<0.001$ \\
\hline Chloride & $(n=171)$ & $(n=155)$ & \\
\hline On admission & $117 \cdot 7(12.6)$ & $115.6(11.6)$ & \\
\hline 24 hours later & $110 \cdot 3(8.8)$ & $114.9(8.3)$ & $P<0.001$ \\
\hline At discharge & $102 \cdot 0(4 \cdot 1)$ & $105 \cdot 7(2 \cdot 2)$ & $P<0.001$ \\
\hline
\end{tabular}

Serum electrolytes (Table 5). Twenty four hours after hospital admission, electrolyte abnormalities developed in 14 patients in the study group and 29 in the control group who had been normonatraemic and normokalaemic on admission: one from the study and 12 from the control group became hypokalaemic; five study group patients and three controls became hyperkalaemic; seven study group and 13 control children became hyponatraemic; and one study group child and one control became hypernatraemic. These abnurmalities resolved and were not associated with symptoms.

Treatment failure. Oral rehydration treatment was considered to have failed in one patient. His clinical signs of dehydration became worse during the first two hours after admission, his stool output increased to more than $20 \mathrm{ml} / \mathrm{kg}$ per hour, and intravenous therapy was therefore instituted for six hours. Testing of stools for reducing substances was negative and no aetiologic agent was identified.

Complications. During treatment two of the 34 hypernatraemic study group patients $(6 \%)$ developed generalised seizures while six of 24 hypernatraemic patients $(25 \%)$ in the control group developed these seizures $(P=0 \cdot 05)$. The serum glucose and calcium concentrations were normal at this time; serum electrolyte values in both groups were sodium greater than 155 , bicarbonate less than 9 , chloride greater than 134 , and potassium 3.4 to $4.6 \mathrm{mmol} / \mathrm{l}$. These children were treated with diazepam and phenobarbitone, and recovered without sequelae.

Periorbital oedema developed after rehydration in eight children, four from each group. Their serum protein ranged from 4.7 to $6 \cdot 1 \mathrm{~g} / \mathrm{dl}$. The periorbital oedema resolved within three to eight hours after stopping rehydration solutions.

Phlebitis developed at the injection site in five control group patients, and required antibiotic treatment.

Abdominal distention developed in four patients receiving oral rehydration but resolved after the rate of administration of electrolyte A solution was reduced.

Eight hypokalaemic patients in the control group developed paralytic ileus one to three days after admission to hospital. They recovered after being given more potassium in their intravenous fluids.

A total of $46(19 \%)$ children in the study group and $71(30 \%)$ in the control group vomited one to three times during the first six hours of rehydration $(\mathrm{P}<0 \cdot 001)$. 
Mortality. Two patients in the study and five in the control group died three to eight days after treatment had begun. The former two children were under the third centile for weight. ${ }^{5}$ On admission, serum electrolytes were: sodium 136 , potassium $3 \cdot 5$, bicarbonate 15 , and chloride $110 \mathrm{mmol} / \mathrm{l}$ for one of them, and sodium 127 , potassium $2 \cdot 5$, bicarbonate 8 , and chloride $110 \mathrm{mmol} / \mathrm{l}$ for the other. Twenty four hours after admission and before death, serum electrolytes were normal and the patients were rehydrated. They died on the third and seventh day after admission.

The five control children died three to eight days after admission to hospital. Their mean serum sodium, potassium, bicarbonate, and chloride concentrations were $136,3,12$, and $110 \mathrm{mmol} / \mathrm{l}$ on admission; 137, 3.1, 12, and $110 \mathrm{mmol} / \mathrm{l} 24$ hours later; and $138,3 \cdot 3,15$ and $110 \mathrm{mmol} / \mathrm{l}$ before death, respectively. Two of them were below the third centile for weight. $^{5}$

Follow up studies. Follow up studies which were performed randomly at home on 172 study group patients and 169 control children indicated that except for the six patients who had subsequently died, all the others were normal. These six children had been admitted to other hospitals due to subsequent attacks of diarrhoea two to eight weeks after discharge from this hospital. They had received intravenous treatment but had died two to 15 days after admission to hospital.

\section{Discussion}

This study shows that nearly $99 \%$ of the children with severe forms of dehydration, diarrhoea, and vomiting were treated adequately with oral rehydration therapy alone. No serious complications developed in patients in this group and nearly all of them tolerated the rapid volume ( $40 \mathrm{ml} / \mathrm{kg}$ per hour) of electrolyte A solution. Severe vomiting was not a limiting factor in the successful use of oral treatment in any of our patients, although $50 \%$ of them presented with a history of severe vomiting (Table $3)$. In addition, severe diarrhoea which was present in $72 \%$ did not prevent successful oral treatment. The protocol was also safe and effective in the correction of a wide variety of electrolyte abnormalities present on hospital admission (Table 5).

The study indicates that the frequency of vomiting during the first six hours in the orally treated group was lower than in controls $(\mathrm{P}<0.001)$; that the duration of diarrhoea was less in the study group; and that in the same group the weight gain at hospital discharge was greater $(\mathrm{P}<0 \cdot 001)$.
Twenty four hours after admission, the serum potassium concentration in hypokalaemic patients was returning to normal in the study group but was unchanged in controls. This was because potassium intake per $\mathrm{kg}$ was 2.5 times greater in the study than the control group during this period. Similarly, hyperchloraemic metabolic acidosis was corrected more rapidly $(\mathrm{P}<0.001)$ in study group patients as their intake of bicarbonate was 3.4 times that of controls in the first 24 hours and 2.8 times during the entire period of treatment (Table 4).

\section{Conclusion}

We conclude that oral rehydration therapy according to this protocol is successful in treating severe diarrhoea, vomiting, and dehydration, and is superior to intravenous therapy in reducing the complications associated with the treatment of hypernatraemia, in decreasing the duration of diarrhoea, in promoting rapid correction of electrolyte abnormalities, and in allowing a greater weight gain at hospital discharge.

The authors thank the staff of Bahrami Children's Hospital, Dr P Rassadi for laboratory tests, and Mr M Sharifi for assistance in manuscript preparation.

\section{References}

${ }^{1}$ Hirschhorn N. The treatment of acute diarrhea in children: an historical and physiological perspective. Am J Clin Nutr 1980;33:637-63.

2 Oral rehydration therapy (ORT) for childhood diarrhea. Population reports Vol 8, no. 6. Series L, no 2. Baltimore, Md: Johns Hopkins University Population Information Program, 1980.

3 World Health Organization. A manual for the treatment of acute diarrhea. Control of diarrheal disease. WHO. CDD/SER/80.2. Geneva: World Health Organization, 1981.

${ }^{4}$ Sharifi J, Ghavami F. Oral rehydration therapy of severe diarrheal dehydration. Clin Pediatr 1984;23:87-90.

5 National Center for Health Statistics. NCHS growth curves for children, birth-18 years, United States. Hyattsville, Md: National Center for Health Statistics, 1977; DHEW publication no (PHS) 78-1650. (Vital and health statistics, series 11, no 34).

${ }^{6}$ Mohajer S, Badalian K. Studies of diarrheal diseases in Iran. Occurrence of bacterial infection in preschool children on the central plateau of Iran. J Trop Med Hyg 1969;72:265.

7 Skirrow MB. Campylobacter enteritis: a 'new disease'. Br Med J 1977;ii:9-11.

${ }^{8}$ Sheiban F. Modification of the MIF and MF techniques for detecting and preserving intestinal protozoa. Bull WHO 1973;41:419-20.

9 Robson AM. Parenteral fluid therapy. In: Nelson textbook of pediatrics. London: WB Saunders, 1979;284-306.

Correspondence to Dr J Sharifi, Bahrami Children's Hospital, Tehran 16417, Iran.

Received 19 April 1985 